\title{
Constrictive vs. distinctive familiness and the culturing of familiness capital (FamCap)
}

\author{
René van Wyk \\ Gordon Institute for Business Science (GIBS), South Africa. E-mail: vanwyk.rene@gmail.com. Tel: +27 832578857. \\ Fax: +27 866239811 \\ Accepted 27 August, 2012

\begin{abstract}
The special capacity of family firms to perform competently is termed 'familiness'. The construct familiness refers to strategic processes in family firms, based on the unique capabilities and involvement of the family firm owners that enhance business performance. However, the culture of familiness has to be observed cautiously with both its positive (distinctive) and negative (constrictive) attributes. Only when distinctive familiness functions optimally, does it operate as 'familiness capital' (FamCap). As far as could be established, this review introduces the concept of FamCap for the first time as the ultimate performance of familiness. It furthermore explores the unique characteristics that could foster the cultivation of FamCap in family businesses.
\end{abstract}

Key words: Familiness, constrictive familiness, distinctive familiness, familiness capital (FamCap), psychological capital (PsyCap).

\section{INTRODUCTION}

Family businesses, often in the form of micro, small and medium scale industries, globally play an extraordinary role in the progress and advancement of economies (Agarwal et al., 2011; Andrade et al., 2011; Chrisman et al., 2003c; Sharma and Sharma, 2011). The high-quality performance of family businesses and their positive contribution to global economic growth is well recognized (Galve-Górriz and Salas-Fumás, 2011). Family firms are often pioneers in opportunity development in different industries around the world, acknowledged by an evolutionary vigour that produces positive cultures of trust, synergy and entrepreneurial innovation (Dyer and Dyer, 2009). Notwithstanding the important contribution of family businesses to global economies being the dominant form of enterprise (Long and Mathews, 2011; Sharma and Sharma, 2011), it is a largely neglected field of study (Jones, 2006). Nuñez-Cacho and Grande (2012) indicate that socio-emotional variables should be considered in the measuring of family business performance.

The different strengths that support the vigour in family businesses are often concealed processes that form part of dynamic interactions between the family business owners, employees, stakeholders, customers and suppliers (Dyer and Dyer, 2009). However, there seems to be a core culture of competence in family businesses in which their performance is anchored, called 'familiness' (Habbershon et al., 2003). The familiness dynamics include idiosyncratic interactions that evolve to create the performance excellence associated with many family firms (Habbershon et al., 2003; Pearson et al., 2008). Pearson et al. (2008) emphasize the importance of the ground breaking exploration of the unique construct of familiness in family firm research. Pearson et al. (2008) and Sharma (2008) argue that the nomological constituency of familiness needs to be conceptualized further and that its antecedents and outcomes need to be determined. It is furthermore important to explore the antecedents and consequences of familiness to prevent it becoming a confusing umbrella concept (Sharma, 2008). This paper therefore attempts to expand on the functioning of the familiness construct as introduced by Habbershon and Williams (1999), Habbershon et al. (2001), and Habbershon et al. (2003) by introducing the concept of FamCap.

Prior published studies appear not to have examined the concept of familiness and its optimal functioning in the form of FamCap. Hence, this analysis contributes to the family firm literature in two ways. Firstly, it explores the optimal flow of familiness and its potential to function 
as FamCap. Secondly, it investigates different perceptions that could contribute to the synergetic functioning of FamCap as a strategic advantage in family firms. In this discussion the theoretic perspective of familiness is explored from a resource-based view. Furthermore the functioning of both positive and negative forms familiness is discussed, followed by the exploration of the development of FamCap. Different constructs that could contribute to the promotion of FamCap are explored.

\section{THEORETIC PERSPECTIVE: RESOURCE-BASED VIEW}

The original description of familiness uses a resourcebased view (RBV), in other words, it sees the competitive advantage that family firms enjoy due to the distinct accumulation of their resources and capabilities (Habbershon and Williams, 1999). Pearson et al. (2008) confirm this theoretical approach regarding the different dimensions of the familiness concept in the form of social capital formed by family firm resources and competencies. Family firm resources are described as consisting of structural network ties, cognitive shared visions and relational dimensions of trust, norms, obligations and identification, which provide information access to capabilities and associability. Chrisman et al. (2003a) suggest that RBV should take the dynamics of both the financial and non-financial resources into account. RBV sheds some light on familiness as the family firm's biggest asset that develops from idiosyncratic dynamic processes resulting in superior performance (Habbershon and Williams, 1999). RBV allows for a valuable assessment of tangible assets, but especially the intangible abilities and skills that create the unique and distinctive abilities of the family business (Barney, 1991; Poza, 2007). The RBV focuses on the individuals or groups in a firm as participating in uniquely dynamic and complex idiosyncratic interpersonal processes, which include values, beliefs and symbols (Barney, 1991). From a RBV perspective, familiness can be described as the unique and distinctive idiosyncratic resources of family firms that function to the advantage of the business (Habbershon and Williams, 1999; Habbershon et al., 2003; Tokarczyk et al., 2007). It is further described as the vibrant, dynamic interaction and idiosyncratic interpersonal processes that occur between the family, the firm, individuals associated with the firm, and social and physical capital resources (Habbershon and Williams, 1999; Habbershon et al., 2003).

\section{FAMILINESS EQUILIBRIUM: POSITIVE VERSUS NEGATIVE FAMILINESS}

In order to balance the functioning of familiness in a family firm, there needs to be equilibrium between moral values and the requirements of the business. This investigation into the concept of familiness sheds light on both the positive and negative implications of its functioning. Where identity confirmation improves trust and communication in family businesses it could lead to distinctive and positive familiness (Klein, 2008; Milton, 2008). However, if the familiness character is misused for short-term personal advantage, it could lead to negative outcomes and constrictive familiness (Klein, 2008). Constrictive familiness arises from elements such as nepotism, opportunistic decisions and unfavorable selections (Feito-Ruiz and Menéndez-Requejo, 2010). Constrictive familiness is also a symptom of low energy levels in a firm. Low energy is characterized by symptoms such as apathy, inflexibility and inertia (Bruch and Ghoshal, 2003). Conversely, positive familiness is characterized by selfless dedication and the long-term investment perspectives of family businesses (Feito-Ruiz and Menéndez-Requejo, 2010).

\section{Negative 'down side' of familiness}

It is important to note that the functioning of familiness is not always positive and dynamic, as it can also operate negatively and show its 'dark' side. The mixed positive and negative effects of familiness require close examination (Vought et al., 2008). Habbershon et al. (2003) caution that resources and capabilities related to familiness can lead to both the advancement and restriction of family business functioning. A cultural 'darkness' can operate in businesses when values that are practiced contradict official or healthy cultural morals and ethics (Lampe, 2002). Habbershon and Williams (1999) point out that negative cycle of familiness can occur; and that these may be constrictive to the functioning of a family firm. The product of dysfunctional, constrictive familiness can be seen in:

1. Low succession, as only about one third of family businesses are successfully transferred to the next generation (De Massis et al., 2008; Galve-Górriz and Salas-Fumás, 2011; Poutziouris et al., 2004; Poza, 2007). 2. A lack of utilising and integrating the commercial and technical knowledge during generation transfer and dynamic market changes (Agarwal et al., 2011; Chirico and Salvato, 2008).

3. Challenges experienced due to resistance to change (Chirico and Salvato, 2008; Ogbonna and Harris, 2001).

4. Emotional factors which negatively affect the total value of the family business (Astrachan and Jaskiewicz, 2008).

5. Family conflicts (Eddleston et al., 2008).

6 . The potential cost of sibling rivalry (Astrachan and Jaskiewicz, 2008).

7. A too high concentration of family ownership and control may lead to diminished ethical behaviour (O'Boyle et al., 2010). 


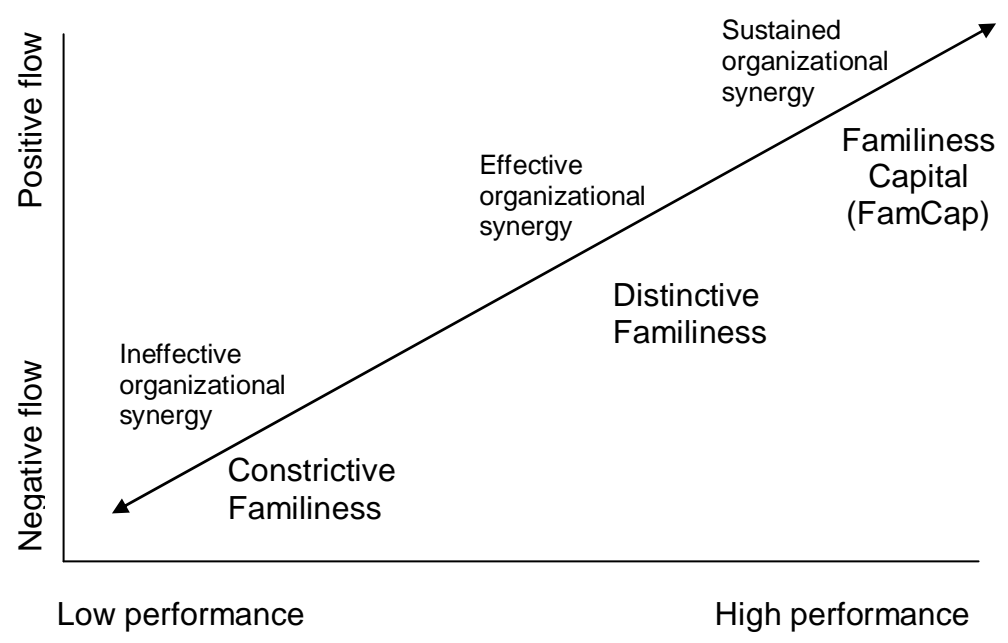

Figure 1. The continuum of constrictive familiness versus distinctive familiness.

8. Power abuse and lack of transparency (Chen and Hsu, 2009; Subramaniam et al., 2011).

9. Management practices that favour family members in family firms show less ethical behaviour (O'Boyle et al., 2010).

10. Should family ownership be too restrictively family owned, the danger exists that this could lead to constrictive familiness (O'Boyle et al., 2010).

One also has to bear in mind that organizational wellness is not solely dependent on positive attitudes. Even well functioning family businesses are not free from conflict and disagreements and are therefore prone to constrictive familiness (O'Boyle et al., 2010). Pelzer (2005) warns that the emphasis on positive discourses and organizational wellness is one-sided, as moral judgment is often regulated by negative emotions. For instance, anger, contempt and disagreements often precede moral reasoning and guide controversial judgements. It would therefore be a fallacy to regard familiness exclusively as a positive form of functioning. It seems that optimal performance is only present in a scenario where capitalising of the familiness culture takes place in positive flow.

\section{Positive 'up side' of familiness}

It seems that familiness, when optimized, functions as a 'flow' of positive family networking in which members of the family and individuals in the family business are engaged. This flow can be compared to the continuous synergetic development and grooming of the mental and emotional capacities of an individual producing psychological capital (PsyCap) (Seligman, 2002). In the workplace PsyCap is cultivated by aligning the flow of personal and organizational goals with job fit (Luthans et al., 2004). Similarly, the flow of familiness that takes place within the functioning of a family firm between the family, employees, stakeholders, customers and suppliers can be regarded as FamCap. It is argued that FamCap is the optimal flow of familiness as a fit and alignment of the dynamic processes and interactions within the firm with the various resources that form its capital: family, social, interpersonal, financial and physical.

\section{Exploring the FamCap Construct}

The construct of FamCap is developed from the concept of familiness. The unique character of family business resources that leads to their competitive advantage has been dubbed 'familiness' (Habbershon and Williams, 1999; Habbershon et al., 2001, 2003). Familiness is defined as the collective synergetic systemic interactions between family members and employees of a family business, leading to the unique character of family firms (Habbershon and Williams, 1999; Habbershon et al., 2001, 2003). Familiness is also described as the different interactions and commitments of the family owners' competency and resources (Chrisman et al., 2003b). The phenomenon of familiness is regarded as the source for the creation and generation of competitive advantage and family firms' wealth (Pearson et al., 2008).

Familiness can be envisaged as a continuum between low and high functioning proficiency (Rutherford et al., 2008) as depicted in Figure 1. At the lower end of the continuum the ineffective organizational synergy and negative flow of familiness is represented by constrictive familiness. The higher end of the continuum represents the promotion of distinctive familiness with effective 


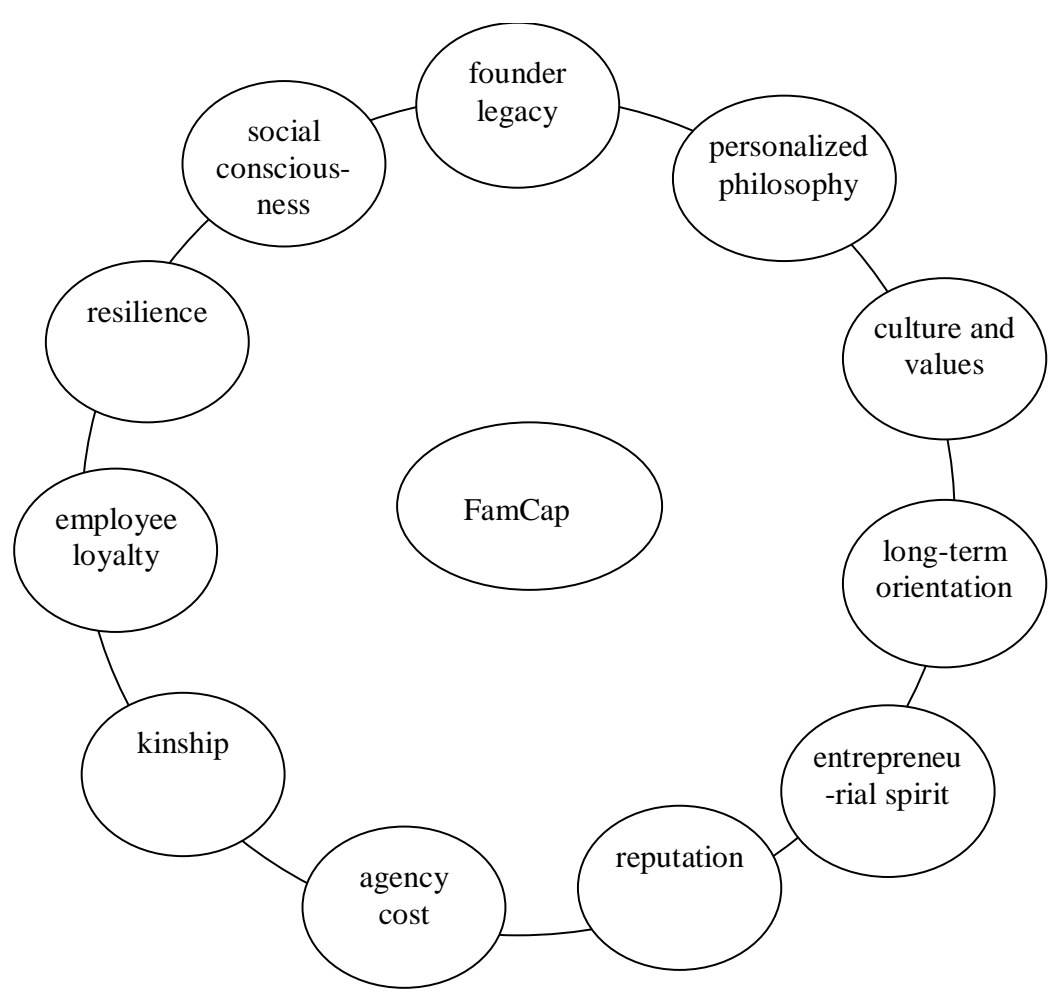

Figure 2. The contributing factors of FamCap.

organizational synergy. Only when optimal familiness is achieved in the form of a vigorous flow of sustained organizational synergy and continuous investment in family firm networking, does FamCap result, as represented in Figure 1.

Figure 1 indicates that as familiness increases, moving into a positive flow of sustained organizational energy, it is converted into FamCap. It appears that a deficiency or imbalance in the functioning of familiness leads to constrictive familiness, whereas the positive functioning of familiness leads to distinctive family firm functioning. Distinctive familiness is the result of a balanced relationship between systems, as opposed to constrictive familiness, where the flow of capital is unidirectional, reducing capital stocks (Sharma, 2008). FamCap accordingly refers to the optimal functioning of familiness. FamCap is regarded as the optimal flow of organizational energy that leads to prolonged synergy and the generational perpetuation of the family firm. FamCap also refers to the successful avoidance of apathetic or lethargic interpersonal processes that restrict the flow of optimal familiness and the formation of FamCap.

\section{Characteristics that support FamCap}

The concept of FamCap provides an explanation for the unique character and the exceptional performance of family businesses in the global market. It is similar to what Seligman (2002) describes in positive psychology as 'building what is right', and what Diener et al. (2005) refer to as 'subjective well-being' embodied in low levels of aversion and higher forms of satisfaction.

Certain core family values seem to be significant factors in avoiding aversion and unifying the family and the business in translating familiness into FamCap. Family firm founders or next generation owners play an important role in perpetuating the construction of their successes and maintaining a culture of value creation. In this way they provide support for the development of subjective well-being, preserving the development of familiness which could lead to the high performance mode of FamCap. Figure 2 depicts the characteristics are considered as contributing to the optimal flow of familiness in the form of FamCap, namely: founder legacy, personalized philosophy, culture and values, long-term orientation, entrepreneurial spirit, reputation, agency cost, kinship, employee loyalty, resilience and social consciousness.

The discussion that follows sheds more light on the contribution of the different characteristics towards the functioning of FamCap.

\section{Founder legacy}

Founder legacy plays an important role in maintaining the 
family values in the business. Imprinting theory explains the long lasting effect that the legacy of the founder has on the vision, guiding principles and strategies of the family firm (Schein, 1983). The founder legacy often serves as a guideline for the functioning of the enterprise over many generations (Venter, 2007). This phenomenon of following the guidelines and basing decisions on the principles laid down by the founder is called 'founder legacy centrality' (Kelly et al., 2000). It is important that family firms see to it that the founder legacy is carried over in acquisitions to demonstrate the commitment and sincerity of the family owners (Steen and Welch, 2006). In order to sustain the founder legacy, it is of strategic importance that a member of the family takes over in the succession of the business, as he/she usually has a lifelong knowledge of the firm and a historical liaison with suppliers, clients and staff (Royer et al., 2008).

\section{Personalized philosophy}

The personalized philosophy and long-term vision of a family firm provides security and stability to its members, whether they are owners or employees. The values of the family often hold philosophies that control, preserve and sustain the business (Presas et al., 2011). It is as if a family firm has a personality that propagates the values, morals and ethics of the family, manifesting as the soul of the business (Hubler, 2009). Ethical behavior and core values are often encouraged more informally through role modeling in family businesses, than through the formal core value statements of non-family businesses (Belak et al., 2012).

Family firms tend to focus on a shared vision that conjoins the family owners and the firm, limiting conflict and advancing performance (Hughes, 2007). As family businesses grow and next generation successions take place, upgrading of old practices and ideas require attention. A farsighted 'family champion' often plays a critical role in redirecting the business from its mooring established activities to visionary future entrepreneurial actions (Salvato et al., 2010). Transformation usually takes place in family businesses through an institutional champion who carries out much needed transformations and gets rid of old methods that need to be abandoned (Parada et al., 2010).

\section{Culture and values}

Business culture plays an important role in the functioning and accomplishments of businesses. At the heart of organizational culture are the unconscious 'taken-for-granted' beliefs of individuals that guide their preferences and actions (Schein, 1985: 14). Businesses have become increasingly conscious of the influence of the culture of a business on its financial performance
(Lampe, 2002). For instance, identification with the organizational culture can support the mobilization of energy in the pursuit of the organization's goals (OrtonJones, 2003; Jones, 2006).

Family firms tend to form a close association between the family owners and the employees. An organizational energy develops in family firms where there is a close linkage between the family and the firm, and the values, principles and preferences of the family becoming the ethos and metaphorical foundation of the functioning of the firm (Jones, 2006).

\section{Long-term orientation}

Lucrative transgenerational family businesses have a long-term orientation of succession as a common goal (Miller and Le Brenton-Miller, 2005). The long-term orientation of family firms often encourages international innovation initiatives (Claver et al., 2009). Family businesses are especially sensitive to and alert in recognizing and swiftly reacting to international opportunities through creating new formal ties (Kontinen and Ojala, 2011). Family firm owners are willing to make huge sacrifices for the business to reach long-term goals, for instance working long hours, often for lower remuneration than the managers (Levie and Lerner, 2009). When employees observe the devotion and dedication of the leaders in the family business, they are inclined to show greater commitment (Zahra et al., 2008) leading to identity confirmation (Klein, 2008). The identity confirmation of non-family employees has a significant positive relationship with the profitability and success of family firms (Vallejo, 2009).

\section{Entrepreneurial spirit}

An entrepreneurial spirit is fundamental to the viability, prosperity and competitiveness of a family business. Family firm owners have a special ability to perpetuate the creation of new ventures successfully through purposeful willpower (Aronoff and Baskin, 2005). However, the seeking and embarking on new ventures is not done blindly and recklessly. Family firms operate conservatively and are risk aversive compared to nonfamily firms (Bonilla et al., 2010). Second-generation family owners often become risk averse in an attempt to preserve the family wealth (Molly et al., 2010). Growth rates sometimes decrease after the second generation takeover, but are affected less by succeeding generation transitions. The constraining effects of being too risk averse could lead to constrictive familiness and must not be underestimated. The higher the family firm ranks in conservatism, the more it is significantly negatively associated with research and development expansion; this is an important feature in maintaining competetiveness (Chen and Hsu, 2009). 
Successful family firms are well known for their commitment to the access and integration of knowledge (Chirico and Salvato, 2008). New knowledge that can add value to the family firm is purposefully sought and integrated despite obstacles and potential conflicts that may hamper attempts to do so.

\section{Reputation}

The reputation of the family business is dear to the heart of the owners and generates a strong sense of responsibility. Family firm owners identify with their businesses to a large extent and make a great effort to guard and protect its reputation (Block, 2010). Accordingly, family firms prioritize the needs of their customer service (Danes et al., 2008; Venter, 2007). A relationship of trust often develops between the family firm and its customers, suppliers and employees through historical associations (Royer et al., 2008; Sundaramurthy, 2008). This is confirmed by a US study of 572 family firms indicated that $44.6 \%$ saw their relationship with their customers as the most important objective of their business (Danes et al., 2008).

\section{Agency cost}

Family firms often represent efficient organizational governance (Kang, 2000). On the one hand family ownership and management can lead to alignment between management and shareholders' interest, leading to the convergence of interest, thereby reducing agency cost (Jabeen and Shah, 2011). On the other hand, too much family insider interest may result in information asymmetry, especially in developing countries where corporate governance is not protected well (Claessens et al., 2000).

\section{Kinship}

The characteristic of familiness also evolves from the kinship that often grows between family business owners and employees. This explains how employees often come to see themselves as 'part of the family' in a paternalistic, caring family business (Jones, 2006: 172). Such a fictive parental relationship can contribute to an organizational energy of shared beliefs and a deep feeling of involvement in achieving the success of the company. Organizational energy is regarded as the dynamic interchange between 'emotional, cognitive and physical states' within a firm (Bruch and Ghoshal, 2003: 45).

\section{Employee loyalty}

Family firm owners deem their employees to be an important asset. If a negative relationship exists between ownership of the family firm it results in the harmful action of downsizing. Family firms are renowned for continuous loyalty and accountability to their employees in times of economic recession (Stavrou et al., 2007) and when markets are depleted (Cater and Schwab, 2008; Lee, 2006), avoiding downsizing at any cost (Block, 2010). Notwithstanding the turmoil caused by market lows, family firms prefer to take the long-term altruistic step of retaining their staff while rather cutting on other costs (Cater and Schwab, 2008; Lee, 2006). On the other hand they pursue employment growth when the economy recovers (Kellermanns et al., 2008). This backing up from the family leads to a strong bond of mutual support and dedication between business owners and their employees.

\section{Resilience}

Family firms seem to have a special capacity for reigniting their existence during difficult times. When faced with adversity, family firms tend to generate turnaround strategies for ensuring the survival of the company (Cater and Schwab, 2008). Their expertise in turning around the family business is mainly embedded in the strategic coordination of long-term social relationships and the acquiring of knowledge from external expertise. Family firms are vigilant in scanning for threats from their competition using shared mental models to strategise (Kellermanns and Barnett, 2008). Consequently family firms in general have the capacity to function in both profitable and adverse economic conditions (Levie and Lerner, 2009).

\section{Social consciousness}

There is a social consciousness that is typical of family firm operations. They are known for their sincere interest and involvement in the communities they serve (Ward, 2004). According to a Fortune 500 Companies' report, family firms have a higher number of social responsibility policies than non-family businesses (Stavrou et al., 2007). The philanthropic orientation of family businesses seems to be under reported to a large degree (Lester and Canella, 2006) and under estimated (Venter, 2008). This may possibly due to their sensitivity to media exposure and their preference for privacy (Poutziouris et al., 2004). As family firms are based mainly in rural areas, the families running these businesses are in a unique position to understand the needs of their communities (Niehm et al., 2008). A reciprocal association develops, benefiting both community and family business.

The ideal would be to optimally nurture and develop the discussed familiness resources to function as FamCap. By cultivating these resources family business should 
manage to capitalise on the optimal zone of familiness, by functioning as FamCap.

\section{DISCUSSION}

As a family provides support to the functioning of its members, so does FamCap act as the foundation of functional excellence for a family firm. This paper has provided a basis of an exploration of the characteristics of familiness and its optimal functioning in the form of FamCap. The long-term endurance of FamCap adds economic value to the performance potential and generation transition success of family businesses.

Different insights have been gained from this discussion. Firstly, this article presents the construct of FamCap. Secondly, the optimal functioning of familiness in the form of FamCap is explained. Thirdly, different variables relating to FamCap are discussed. Arguments are provided that show how cultural and organizational conditions foster FamCap. It is also noted that family businesses can fall into constrictive functioning; firms should be aware of factors that have a negative influence on familiness. The article provides argumentative support for the reasoning that 'familiness' is a potential determinant of 'resource-building and value creation' as suggested by Habershon and Williams (1999), Habbershon et al. (2003), Pearson et al. (2008) and Sharma (2008). It takes this argument further by exploring the benefits of familiness in its optimal functioning as FamCap.

The aim of this paper has been to investigate the concept of familiness and its potential to function optimally as FamCap. This paper furthermore explored the different resource factors that lead to the synergetic functioning of FamCap. FamCap is founded in the individual culture and specialist field in which the business operates. Different features play a role in support of FamCap. It is as if a personality exists in a family firm that acts as an agent in sustaining its cultural values. The embodiment of the culture is found in various virtues. Founder legacy has a long-term influence on the family, often lasting over many generations. Founder legacy is often strategically preserved and honoured by owners and employees as a core value of the family business. Preserving the entrepreneurial spirit is strategically planned without being risk inclined. Family businesses tend to face challenges head on and are creative in generating constructive solutions and turnaround strategies during difficult economic times. A relationship of trust develops between family firm owners and employees, customers and the communities they serve. The loyalty of family firms to their employees during difficult economic times and their philanthropic support to the needy in their communities strengthens the bond between the parties.

Future research needs to be carried out to refine the pragmatic evidence for the existence of FamCap and methods to measure it empirically. Factors that influence FamCap should be utilised to serve as a platform for the training and judgment of family firm successors. It is furthermore important that the culture that supports FamCap should be kept alive in the process of generation transition. Research should also address the following questions: What are the factors contributing to FamCap? Does a FamCap culture in a family business lead to important employee outcomes such as low turnover and commitment to the family firm? Does FamCap improve the transition of family firms from one generation to the next? Does familiness have both advantages and disadvantages, or is it the presence of familiness in itself that leads to advanced performance and a lack thereof that leads to constrictive family business functioning? What is the relationship between FamCap and familiness on the one hand and other work-related factors, such as turnover, absenteeism, satisfaction, commitment and organizational citizenship behavior on the other? Is FamCap more prevalent in family business groups compared to small family businesses? Which factors lead to constrictive familiness?

The presence of FamCap in family businesses should be evaluated to assist owners to take strategic actions that build commitment and foster FamCap as a source of competitive advantage and to enable successful generation transitions. Family business owners should take steps to cultivate, promote and nurture the functioning of FamCap. At the same time, family owners should be sensitized to factors that damage familiness and constrict its functioning. Business owners should also explore different avenues that can prevent restrictive familiness.

\section{CONCLUSION}

This literature review indicates that virtues seem to exist in family businesses, contributing to the optimal functioning of familiness in the form of FamCap. However the risk always exists that certain values on the familiness continuum could lead to constrictive familiness, weakening family business functioning. The discussion acknowledges that family businesses are challenged by negative influences that could hamper potential familinest. Family businesses should be on the lookout for weak links that can lead to constrictive familiness and consequent failure of FamCap. It is concluded that the existence of a culture of FamCap yields strategic advantages and value creation. FamCap, which is explained by the non-financial performance of the family business to some extent, leads to financial returns, as well as to the perpetuation of family businesses.

\section{REFERENCES}

Agarwal YM, Garg TK, Wani VP (2011). Productivity improvement of 
sports goods industrial cluster in Meerut India. J Mech. Eng. Res. 4(1):28-35.

Andrade DM, De Lima JB, Antonialli LM, De Muyder CF (2011). The family social capital impact in practices of learning, change and innovation in entrepreneurial family businesses. Afr. J. Bus Manag. 5(33):12819-12828

Aronoff G, Baskin O (2005). Effective Leadership in the Family Business. Marietta, GA: Family Enterprises.

Astrachan JH, Jaskiewicz $\mathrm{P}$ (2008). Emotional returns and emotional costs in privately held family businesses: advancing traditional business valuation. Fam. Bus. Rev. 21:139-149.

Barney JB (1991). Firm resources and sustained competitive advantage. J. Manag. 17:99-120.

Belak J, Duh M, Milfelner B (2012). The use of institutional measures for business ethics implementation in family and non-family businesses: Does a family matter? Afr. J. Bus Manag. 6(1):430-440.

Block J (2010). Family management, family ownership, and downsizing: evidence from S\&P 500 firms. Fam. Bus. Rev. 23:109-130.

Bonilla CA, Sepulveda J, Carvajal M (2010). Family ownership and firm performance in Chile: a note on Martinez et al.'s evidence. Fam. Bus. Rev. 23:148-152.

Bruch H, Ghoshal S (2003). Unleashing organizational energy, MIT Sloan Manage. Rev. 45(1):45-51.

Cater J, Schwab A (2008). Turnaround strategies in established small family firms. Fam. Bus. Rev. 21:31-50.

Chen H, Hsu W (2009). Family ownership, board independence, and R\&D investment. Fam. Bus. Rev. 22:347-362.

Chirico F, Salvato C (2008). Knowledge integration and dynamic organizational adaptation in family firms. Fam. Bus. Rev. 21:169-181.

Chrisman JJ, Chua JH, Litz R (2003a). A unified systems perspective of family firm performance: an extension and integration. J. Bus. Vent. 18:467-472.

Chrisman JJ, Chua JH, Sharma P (2003b). Current trends and future directions in family business management studies: toward a theory of the family firm. Accessed online 8 August 2005 at http://www.usasbe.org/knowledge/whitepapers/ chrisman2003.pdf.

Chrisman JJ, Chua JH, Zahra S (2003c). Creating wealth in family firms through managing resources: comments and extensions. Entrep. Theor. Pract. 27(4):359-365.

Claessens S, Djankov S, Lang LHP (2000). The separation of ownership and control in East Asian corporations. J. Finan. Econ. 58(102):81-112

Claver E, Rienda L, Quer D (2009). Family firms' international commitment: The influence of family-related factors. Fam. Bus. Rev. 22:125-135

Danes SM, Loy JT, Stafford K (2008). Business planning practices of family-owned firms within a quality framework. J. S. Bus. Manag. 46:395-421.

De Massis A, Chua JH, Chrisman JJ (2008). Factors preventing intrafamily succession. Fam. Bus. Rev. 21:183-199.

Diener E, Lucas RE, Oishi S (2005). Subjective well-being. The science of happiness and life satisfaction. In CR Snyder, S J Lopez (Eds). Handbook of Positive Psychology. Cape Town: Oxford University Press.

Dyer WG, Dyer WJ (2009). Putting the family into family business research. Fam. Bus. Rev. 22:216-219.

Eddleston KA, Otnodo RF, Kellermanns FW (2008). Conflict, participative decision-making, and generational ownership dispersion: A multilevel analysis. J. S. Bus. Manag. 46:456-484.

Feito-Ruiz I, Menéndez-Requejo S (2010). Family firm mergers and acquisitions in different legal environments. Fam. Bus. Rev. 23:60-75.

Galve-Górriz C, Salas-Fumás V (2011). Growth strategies, professionalization, ownership structure and performance across generations of a family firm. Afr. J. Bus. Manag. 5(9):3589-3604.

Habbershon TG, Williams M, Macmillan I (2001). A Unified Systems Theory of Family Firm Performance. Enterprising Families Initiative, Working Paper \#103. Philadelphia, PA: University of Pennsylvania.

Habbershon TG, Williams M, Macmillan I (2003). A unified systems perspective of family firm performance. J. Bus. Vent. 18:451-465.

Habbershon TG, Williams MA (1999). Resource Based Framework For Assessing the Strategic Advantages of Family Firms. Enterprising Families Initiative, Working Paper \#101. Philadelphia, PA:
University of Pennsylvania.

Hubler TM (2009). The soul of family business. Fam. Bus. Rev. 22:254258

Hughes C (2007). Resolving conflict in the family business. LPG Mag 67(5):14.

Jabeen M, Shah AA (2011). A review on family ownership and information asymmetry. Afr. J. Bus Manag. 3(35):13550-13558.

Jones AM (2006). Culture, identity and motivation: the historical anthropology of a family firm. Cult. Org. 12(2):169-183.

Kang D (2000). The impact of family ownership on performance in public organizations: A study of the U.S. Fortune 5000, 19621994 2000. Acad. Manage. Meet Toronto, Canada.

Kellermanns FW, Barnett T (2008). Commentary: What were they thinking? The role of family firm mental models on threat recognition. Entrep. Theor. Pract. 23:999-1006.

Kellermanns FW, Eddleston KA, Barnett T, Pearson A (2008). An exploratory study of family member characteristics and involvement: Effects on entrepreneurial behaviour in the family firm. Fam. Bus. Rev. 21:1-14.

Kelly LM, Athanassiou N, Critteden WF (2000). Founder centrality and strategic behaviour in the family-owned firm. Entrep. Theo. Pract. 25:27-42.

Klein SB (2008). Commentary and extension: moderating the outcome of identity confirmation in family firms. Entrep. Theor. Pract. 32:10831088.

Kontinen T, Ojala A (2011). International opportunity recognition among small and medium-sized family firms. J. S. Bus. Manag. 49(3):490514.

Lampe AC (2002). The silencing of voices: The Corporate "Darkness" nobody hears. Cult. Org. 8(2):129-144.

Lee $J$ (2006). Family firm performance: Further evidence. Fam. Bus Rev. 19:103-114.

Lester RH, Canella AA (2006). Interorganizational familiness: How family firms use interlocking directorates to build community-leve social capital. Entrep. Theor. Pract. 30:755-775.

Levie J, Lerner M (2009). Resource mobilization and performance in family and nonfamily businesses in the United Kingdom. Fam. Bus. Rev. 22:23-38.

Long RG, Mathews KM (2011). Ethics in the family firm: Cohesion through reciprocity and exchange. Bus. Eth. Quart. 21(2):287-308.

Luthans F, Luthans KW, Luthans BC (2004). Positive psychological capital: going beyond human and social capital. Bus. Hortz. 47:45-50.

Miller D, Le Brenton-Miller I (2005). Managing for the Long Lun Lessons in Competitive Advantage from Great Family Businesses. Boston, MA: Harvard Business School Press.

Milton LP (2008). Unleashing the relationship power of family firms: identity confirmation as a catalyst for performance. Entrep. Theor Pract. 32:1063-1081.

Molly V, Laveren E, Deloof M (2010). Family business succession and its impact on financial structure and performance. Fam. Bus. Rev. 23:131-147.

Niehm LS, Swinney J, Miller NJ (2008). Community social responsibility and its consequences for family business performance. Jour. S. Bus. Manage. 46:331-350.

Nuñez-Cacho P, Grande FA (2012). Family businesses: How to measure their performance. Afr. J. Bus Manage., 6(12): 4612-4621.

O'Boyle EH, Rutherford MW, Pollack JM (2010). Examining the relation between ethical focus and financial performance in family firms: an exploratory study. Fam. Bus. Rev. 23:310-309.

Ogbonna E, Harris LC (2001). The founder's legacy: Hangover or inheritance? Brit. J. Manag. 12:13-31.

Orton-Jones C (2003). Energy indes: can company culture be measured? Eurobus. 5(6):68-69.

Parada MJ, Nordqvist M, Gimeno A (2010). Institutionalizing the family business: the role of professional associations in fostering a change of values. Fam. Bus. Rev. 23:355-372

Pearson QW, Carr JC, Shaw JC (2008). Toward a theory of familiness: a social capital perspective. Entrep. Theor. Pract. 32:949-969.

Pelzer P (2005). The hostility triad: the contribution of negative emotions to organizational (un-)wellness. Cult. Org. 11(2):111-123.

Poutziouris PZ, Steier L, Smyrnios KX (2004). Guest editorial. A commentary on family business entrepreneurial developments. Int. J. 
Entrep. Behav. Res. 10:7-11.

Poza EJ (2007). Family Business. $2^{\text {nd }}$ ed. London: Thomson.

Presas P, Muňoz D, Guia J (2011). Branding familiness in tourism family firms. Brand Manag. 18(4/5):274-284.

Royer S, Simons R, Boyd B, Rafferty A (2008). Promoting family: a contingency model of family business succession. Fam. Bus. Rev. 21:15-30.

Rutherford MW, Kuratko DF, Holt DT (2008). Examining the link between "familiness" and performance: can the F-PEC untangle the family business theory jungle? Entrep. Theor. Pract. 32:1089-1109.

Salvato C, Chirico F, Sharma P (2010). A farewell to the business: championing exit and continuity in entrepreneurial family firms. Entrep. Reg. Dev. 22(3/4):321-348.

Schein EH (1983). The role of the founder in creating organizational culture. Org. Dyn. 12:13-28.

Schein EH (1985). Organizational Culture and Leadership. San Francisco, CA: Jossey-Bass.

Seligman MEP (2002). Authentic happiness: using the new positive psychology to realize your potential for lasting fulfilment. New York, NY: Free Press.

Sharma $P$ (2008). Commentary: familiness: capital stocks and flows between family and business. Entrep. Theor. Pract. 32:971-977.

Sharma P, Sharma $S$ (2011). Drivers of proactive environmental strategy in family firms. Bus. Eth. Quart. 21(2):309-334.

Stavrou E, Kassinis G, Filotheou A (2007). Downsizing and stakeholder orientation among the Fortune 500: does family ownership matter? J. Bus. Eth. 72:149-162.

Steen A, Welch LS (2006). Dancing with giants: acquisition and survival of the family firm. Fam. Bus. Rev. 15:289-300.

Subramaniam R, Devi SS, Marimuthu M (2011). Investment opportunity set and dividend policy in Malaysia. Afr. J. Bus. Manag. 5(24):1012810143

Sundaramurthy C (2008). Sustaining trust within family businesses. Fam. Bus. Rev. 21:89-102.

Tokarczyk J, Hansen E, Green M, Down J (2007). A resource-based view and market orientation theory examination of the role of "familiness" in family business success. Fam. Bus. Rev. 20:17-31.
Vallejo MC (2009). The effects of commitment of non-family employees of family firms from the perspective of stewardship theory. J. Bus. Eth. 87:379-390.

Venter WP (2007). The role of familiness in the success and failure of family business groups. Unpublished DCom thesis. University of Johannesburg: Johannesburg.

Venter WP (2008). Ubuntu and social capital factors in family businesses. SA J. Entrep. S. Bus. Manag. 1:66-93.

Vought KL, Baker LT, Smith GD (2008). Practitioner commentary: moving from theory to practice in family business research. Entrep. Theor. Pract. 32:1111-1121.

Ward JL (2004). Perpetuating the family business: Fifty lessons learned from long-lasting, successful families in business. New York, NY: Palgrave MacMillan.

Zahra SA, Hayton JC, Neubaum DO, Dibrell C, Craig J (2008). Culture of family commitment and strategic flexibility: the moderating effect of stewardship. Entrep. Theor. Pract. 32:1035-1054. 